\title{
CANIBALISMO NO BRASIL DESDE 1500... ${ }^{1}$
}

\author{
CANNIBALISM IN BRAZIL SINCE 1500...
}

Maria Thereza Alves ${ }^{2}$

Em uma determinada noite, em Berlim, cheguei em casa muito feliz: dancei e pulei de alegria. Eu tinha ido para uma conferência sobre documentários brasileiros onde, pela primeira vez, os brasileiros de raça mestiça participaram. Deixem-me ser clara: a conferência incluiu pessoas que não eram os descendentes de europeus. Até aquele momento, eurobrasileiros controlavam o discurso sobre cinema e quase todas as outras áreas do Brasil. Certamente eles têm controlado as artes visuais, que são fortemente influenciadas por artistas descendentes de europeus - e a definição deles do que o discurso da arte poderia ser. Isto é, em um país que tem a segunda maior população negra do mundo, perdendo apenas para a Nigéria.

Essa conferência, "Political Documentary Films in Brazil", foi realizada em novembro de 2011 na Haus der Kulturen der Welt, em Berlim, com filmes anteriormente apresentados no Festival Internacional de Cinema do Rio de Janeiro, selecionados pela organizadora do Festival, llda Santiago. A mesa da discussão contou com a Sra. Santiago, no centro, ladeada pelos cineastas: à esquerda dela, quatro jovens brasileiros de origem mestiça e à direita quatro euro-brasileiros, dois dos quais eram mulheres (três, se incluirmos a Sra. Santiago). A divisão visível era apenas uma reafirmação da presença colonial no Brasil.

1 Ensaio originalmente publicado em Berlim, em Berlim, em 7 de novembro 2013. Agradecemos à autora pela gentileza no intercâmbio de seus trabalhos e pela autorização para publicarmos esta versão em português, bem como pela mediação com Jimmie Durham e Richard Hill, que também foram muito gentis em compartilhar seus escritos.

2 Artista plástica, militante ativista das causas indígenas e da defesa da vida no planeta. 
A tensão devido à raça (e, portanto, de classe) e as origens dos dois grupos cresceu durante a discussão e, finalmente, tornou-se pública, pelo menos para aqueles que poderiam reconhecer o que estava acontecendo. Creio que a tensão passou despercebida pelo público alemão. Essa tensão veio à tona quando Sandra Kogut, sentada ao lado euro-brasileiro da mesa, agradeceu aos jovens mestiços por seu ponto de vista (não é fantástico como as elites têm o privilégio da "perspectiva histórica" enquanto o resto de nós simplesmente tem "pontos de vista?”) Ela disse que deve ser difícil para eles serem sempre convidados para fazer filmes sobre a mesma coisa - as favelas, onde vivem. Ela disse que era importante, no cinema, ter um olhar refrescado - para ser capaz de ver as coisas de novas maneiras. $\mathrm{O}$ que estava implícito era que não seria possível para qualquer um desses moradores da favela atingir um nível profissional ou interessante no cinema. Luciano Vidigal, um dos cineastas de raça mestiça, inclinou a cabeça para olhar para o teto. Reconheci esse gesto como a postura adquirida por quem lida com as diversas situações no Brasil, estruturadas para garantir que os descendentes de europeus estejam no poder. Luciano explicou que, com os olhos deles, aqueles que vivem nas favelas agora estavam vendo. O que estava implícito era que aqueles que vivem nas favelas agora estavam olhando para os euro-brasileiros que têm controlado o cinema e, portanto, para a representação de todos os brasileiros até agora. Somente nos últimos anos temos nos visto representados no cinema ou em outras manifestações culturais em trabalhos que são tanto feito por nós quanto que nos representam. No passado, havia apenas representações feitas por eles sobre nós.

Tamar Guimarães, artista euro-brasileira, durante uma conversa que tivemos, explicou que, no Brasil, “não podemos definir um 'nós' e um 'eles' com clareza." Uma vez que os sistemas de privilégios raciais nesse país não reconhecem nenhuma ambiguidade, temo que eu também vou continuar a escrever sem tais nuances.

Cadu Barcellos, um outro jovem cineasta mestiço, acrescentou: "Nosso olhar não é melhor nem pior do que o de ninguém... é singular como qualquer outro... mas o olhar de quem sofre, direta ou indiretamente, deve ser ouvido". 
Notei que, quando Sandra começou seu desafio paternalista de olhar com um "olhar refrescado", uma mulher jovem brasileira de classe média alta, na plateia (o tipo europeu com o cabelo longo, que pode ser reconhecido de imediato), olhou para o outro lado do corredor, para uma jovem brasileira do mesmo tipo. Ficou claro que ambas simpatizavam com Sandra contra os homens de raça mestiça e elas caçoaram quase silenciosamente quando Cadu começou sua resposta.

A atitude condescendente de Sandra Kogut logo desencadeou o ódio de classe de Eryk Rocha, filho de Glauber Rocha. Ele também é um cineasta, sentado do lado euro-brasileiro da mesa. Ele começou a falar naquele tom superior de voz que fez o meu cabelo ficar em pé. Sendo filha de uma empregada doméstica, eu sou sensível às tentativas daqueles que são poderosos de explorar as suas dominâncias, e minha reação é sempre tentar sair da situação o mais rápido possível.

Eryk Rocha fez um grande show de olhares para o lado mestiço da mesa, tornando óbvio que ele não conhecia nenhum dos nomes dos cineastas daquele lado. A mensagem era clara, que ele não os achava interessantes o suficiente para sequer se preocupar em saber seus nomes e, é óbvio, ele não iria lidar com eles socialmente. Ele finalmente pronunciou o nome de Cadu, em tom arrogante de incredulidade, dizendo: "Cadu, Cadu, esse é o seu nome?" - indicando espanto de que se tratava de um nome real.

Eryk passou a dizer a Cadu que o seu trabalho sobre as favelas era importante, mas que não estavam ali para discutir política, mas poética. Isso apesar do título da palestra ser "Political Documentary Films in Brazil". Talvez ele também tivesse esquecido que, no início da noite, o grande Silvio Tendler tinha afirmado que "cinema é política" (devo observar que Tendler também estava sentado no lado euro-brasileiro da mesa, embora tivesse tido a gentileza de admitir sua origem de classe média, o que é óbvio para os brasileiros).

Wagner Novais, do lado mestiço da mesa, afavelmente respondeu: "Eu acho que a democratização da cultura (dá) novos prismas para aquela realidade, para o pessoal que vem dessa origem, que trabalha com cinema... há um processo formal que todo mundo passa: faculdade, curso 
de especialização, não estamos privados de um discurso estético, artístico e poético. Claro que devo minha especificidade à minha origem, à minha vivência".

No final da noite, durante as perguntas, uma jovem mulher afrobrasileira estudando para seu doutorado em Berlim disse: "Eu gostaria de agradecer a possibilidade de estar aqui conversando com brasileiros de diferentes cores, de olhares negros, brancos". Nós duas estávamos tão contentes com este tão esperado (e, até aquele dia, inimaginável) momento em que os brasileiros não-brancos eram, de fato, incluídos publicamente em uma discussão sobre cultura no Brasil.

Em seguida, fui para casa e dancei para comemorar um Brasil de novas possibilidades. Sandra Kogut e Eryk Rocha pareciam ter nada menos do que declarado guerra; demonstrando que essas elites vão continuar, como todas as elites fazem, a não compartilhar o poder. Frente à possibilidade de serem desafiados, eles declararam de forma surpreendentemente insensível e sem constrangimento algum, sua intenção de lutar contra os cineastas de ascendência não-europeia. Mas nós já sabíamos disso. É o que as elites brasileiras estão fazendo desde o século XVI. Mas agora o teto começa a cair sobre eles.

Alguns anos atrás fui convidada pela artista Tamar Guimarães para participar de um debate sobre pós-colonialismo. Conheci Tamar, quando ela era estudante de arte e me pediu uma crítica sobre seu trabalho. Eu não gosto de participar de debates sobre o pós-colonial no Brasil porque, inevitavelmente, sempre acabam mal. No entanto, como Tamar, foi criada na Europa e aceitei por pensar que talvez as coisas pudessem ser diferentes. O fato é que, do ponto de vista indígena, não houve um fim à colonização em nenhum lugar das Américas. Pós-colonização é um fenômeno europeu - sim, naqueles países que perderam suas colônias devido à luta dos povos nativos dessas colônias. Nas Américas a população indígena continua a ser colonizada pelos descendentes dos europeus que permanecem com o poder econômico e político.

É importante mencionar que, em 1994, havia apenas uma pessoa indígena no Brasil com diploma universitário. Na rica província de Minas Gerais (que é abundante em minerais, daí o seu nome obsceno), a primeira 
indígena a receber um diploma universitário, Shirley Djukurna Krenak, o recebeu apenas em 2006, na cidade de Governador Valadares. Shirley foi para uma universidade local pelo sistema de cotas raciais que, embora recente no Brasil, tem permitido a estudantes indígenas se matricularem em universidades financiados pelo governo federal.

Infelizmente, grande parte desses estudantes vem de famílias empobrecidas que vivem longe dos centros urbanos e o custo da viagem, hospedagem, alimentação e material escolar, na maioria das vezes, tornam impossível suas permanências na universidade para continuar e concluir os seus estudos. Há uma alta taxa de desistência. Nesse ponto, uma vez que existem poucas centenas de estudantes indígenas na universidade, qualquer filantropo poderia facilmente resolver esse problema com a doação de fundos para estudantes indígenas. Digamos que, em um total de 600 alunos fosse garantido um subsídio de $€ 5.000$ cada, isso resultaria num total de $€ 3.000 .000$ por ano: uma soma que poderia ser facilmente conferida por, digamos, trinta filantropos. Mulheres ricas poderiam criar um fundo extra para as mulheres indígenas na universidade, especialmente para aquelas que estudam medicina, que é uma educação cara. Imagine o incrível começo de mudança que teríamos em todos os campos do discurso no Brasil - onde o europeu não iria mais dominar o padrão de "normalidade". Teríamos a oportunidade de começar a pensar em maneiras diferentes... de ver de maneiras diferentes.

Voltando a Shirley e Minas Gerais: Eike Batista, (o irmão de Helmut Batista, que comanda residências artísticas, publicação de livros e projetos, etc.) é de descendência alemã-brasileira e foi, em 2012, o homem mais rico do Brasil e o sétimo mais rico em todo o mundo. Ele nasceu em Governador Valadares, em Minas Gerais, onde Shirley e sua família se estabeleceram depois de serem expulsos de sua reserva (como foram todos os outros Krenaks), devido à riqueza mineral em suas terras. Eike iniciou sua carreira de negócios com a compra de ouro na Amazônia e, em seguida, passou a possuir oito minas de ouro entre muitas, muitas outras coisas - o pai de Helmut e Eike foi o ministro de Minas e Energia durante duas administrações presidenciais e ex-presidente da empresa de mineração Companhia Vale do Rio Doce, originalmente baseada em 
Minas Gerais. Shirley Krenak é dos povos indígenas Krenak em Minas Gerais e eles têm visto suas terras sistematicamente reduzidas e destruídas devido à sua riqueza mineral. Shirley explicou que:

Em 1970, mais minerais foram descobertos nas nossas terras e ao mesmo tempo ainda mais fazendeiros começaram a destruir as nossas terras para criar gado, entrando em reconhecido território Krenak. Como resultado das ações desses poderosos grupos políticos, o governo federal declarou em 1970 que, oficialmente, os Krenak estavam extintos. Mas como estávamos muito bem vivos, fomos forçados a retirar-nos das nossas terras e transportados para longínquas reservas com diversos grupos indígenas de linguagens diferentes. Os Krenak que resistiram foram presos e colocados em prisões recémconstruídas, que funcionavam como colônias penais com trabalhos forçados, solitárias, violência diária, tortura e assassinatos. Durante esse tempo muitos de nós viveram clandestinamente com medo de novas migrações forçadas e prisões. O ocultar e negar a nossa identidade étnica foi talvez uma das principais e mais eficientes "armas" na dura luta contra o genocídio. Durante o exílio começamos a nos organizar e alguns anos depois voltamos a caminhar em direção à Reserva Krenak - alguns andaram durante 96 dias. Em 1988 fomos novamente expulsos das nossas terras, as nossas plantações destruídas assim como a nossa escola.

Os Krenak lutaram e conseguiram dar a volta ao decreto de extinção e alguma das suas terras voltarama ser demarcadas em 1997. O juíz disse que se era terra que os Krenak queriam então era terra que lhes seria dada. E de acordo com suas palavras, tudo o que não era terra foi destruído, como árvores de frutos. A reserva hoje tem 4970 hectares de terra infértil para 300 indígenas.

Em 2005, os Krenaks, incluindo Shirley e seus irmãos, montaram um bloqueio de cinquenta horas da ferrovia da Companhia Vale do Rio Doce de (hoje Vale S.A.), que transporta minerais da região. Foi a primeira vez em quase 100 anos que a ferrovia, que atravessa território Krenak e causou tantos danos à comunidade Krenak, não enviou trens sobre suas terras. Foi sob a administração do pai de Helmut e Eike que a Companhia Vale do Rio Doce (Vale S.A.) tornou-se uma das maiores empresas de minerais do mundo. A Vale extrai, entre outras coisas, ferro, o que resulta na contaminação do Rio Doce. Houve desmatamento de terras Krenak, a fim de fornecer madeira para combustível para a ferrovia e o transporte de minerais até o porto. Como resultado do protesto dos Krenaks, a Vale 
finalmente sentou para negociar com a comunidade. Isto resultou em uma compensação de R \$200,00 (cerca de $€$ 66) por mês para cada Krenak, por um período de seis anos. Existem cerca de 300 Krenaks em Minas Gerais que sobreviveram ao genocídio pelos portugueses e, em seguida, o genocídio pelos euro-brasileiros.

Assim, parece que podemos definitivamente descartar o homem mais rico do Brasil de contribuir para uma discussão abrangente da vida nesse país (recentemente, Eike perdeu muito dinheiro. ${ }^{3}$ Ao mesmo tempo, o programa de artistas em residência de seu irmão foi suspenso). O pai de Eike e Helmut também foi responsável por iniciar a mineração a céu aberto naSerra dos Carajás. Apenas 1\% das espécies da área sobreviveram à represa Tucuruí, que foi construída, em parte, para fornecer energia para a mina. A ferrovia foi construída (o pai de Eike e Helmut começou sua carreira como engenheiro ferroviário) nas terras dos Awá Guajá, o que resultou nessas terras sendo rapidamente invadidas por madeireiros, fazendeiros e pequenos agricultores. A população Awá Guajá foi drasticamente reduzida devido às mortes causadas pela defesa de suas terras e também pela introdução de doenças europeias, às quais os Awá Guajá não têm imunidade. Em um período de quatro anos, numa só comunidade com 91 Awá Guajás, apenas 25 sobreviveram. Em outras palavras, repetiu-se exatamente o mesmo tipo de eliminação que aconteceu décadas antes, com a construção da ferrovia em terras Krenak - o pai de Eike e Helmut disse que, com a mina de Carajás, eles eram pioneiros no desenvolvimento sustentável (!).

Agora de volta a Tamar e pós-colonialismo no Brasil. Tamar disse:

Com tamanha circulação de pessoas, é difícil falar de um estrangeiro ou de um brasileiro "original"... E não me refiro a esta falta de origem com desapontamento. Penso nela com alívio. A base instável do Brasil, quando se trata de referências culturais, não é um traço a se lamentar, mas sim uma característica verdadeiramente positiva - algo que deveria nos permitir ver uma relação diferente com o pós-colonial, entendido explicitamente como esse estado fraturado... No entanto, o Brasil sempre teve de lidar com múltiplos pontos de referência, "impurezas" culturais e inconsistências simbólicas no seu centro. Tem sido assim, para melhor, creio eu... Realmente, talvez não

3 No início do mês de julho, envolvido em casos de corrupção ativa e esquema de lavagem de dinheiro, Eike Batista foi condenado pela justiça brasileira a 30 anos de prisão e a pagar multa no valor aproximado de 50 milhões de reais [N.E.]. 
possamos ter como objetivo a descolonização, uma vez que não podemos definir um "nós” e um "eles" com clareza. Talvez tudo o que possamos fazer é falar de entrelaçamentos... Essa foi a forma de, no Brasil, já desde a década de 1920 (com o Manifesto Antropofágico), se propor uma relação diferente e não subalterna com o Ocidente.

Eu gostaria de adicionar um apêndice aqui, uma observação sucinta feita pela socióloga Heloisa Buarque de Hollanda sobre o Manifesto Antropofágico: “(O) auge do modernismo brasileiro, em termos de definição de uma identidade cultural moderna para o país, foi a proposta de um modelo 'antropofágico', que sugere uma atitude, não de imitação dos países centrais, mas de uma apropriação antropofágica dos aspectos 'desejáveis' de diferentes culturas e valores". E ela passa a questionar, apontando: "Na verdade, quem come quem, e o que vale a pena jogar fora durante o banquete antropofágico?" Eu concordo que essa ideia modernista, que teve a função de escorar o nacionalismo, não é mais válida numa época em que a importância de reconhecer as diferenças e dar agência à alteridade é pertinente na construção de novos modelos para a possível sobrevivência da sociedade

Minha resposta a Tamar:

Claro que podemos falar de 'nós' e 'eles' com clareza, partindo do ponto de vista da colonização. Existem os indígenas e os não-indígenas... Não se pode começar a superar a colonização, como é o caso do Brasil, se essa condição não é admitida porque a distinção entre colonizador e colonizado supostamente não pode ser feita. (Camus, um não-indígena argelino, por exemplo, entendia que a descolonização da Argélia não seria possível). A descolonização tem ocorrido em muitas partes do mundo e, talvez, possamos olhar para esses lugares fornecendo modelos possíveis, enquanto estamos num processo de inventar os nossos próprios... Em que medida os não-indígenas estariam confortáveis em concordar que a descolonização? Por exemplo, poderiam os não-indígenas do México, que são apenas uma maioria moderada, concordar que a colonização existe? Até agora não. E o que aconteceria em países como o Brasil, onde os não-indígenas são uma abrangente maioria e os indígenas estão em clara minoria? Os não-indígenas, como é o caso, sentem-se muito confortáveis no pressuposto de que a colonização terminou. Sendo este o caso, o que dizer aos indígenas? Que não existem? Que não contam? Que devem progredir? Como essa situação colonial poderia ser ultrapassada através de um decreto unilateral, determinado pelo colonizador? Através da negação dos indígenas colonizados? Penso que o processo de descolonização 
pode se iniciar através de um processo de observação e, por consequência, da admissão intelectual de que as Américas vivem uma condição colonial...

Gostaria de acrescentar que, mesmo que o Brasil fosse descolonizado, os efeitos da colonização permaneceriam para sempre. Um exemplo é o uso do conceito de canibalismo, desenvolvido no Manifesto Antropofágico de Oswald de Andrade, um euro-brasileiro de uma família eminente. Esse conceito legitima a apropriação das culturas indígenas e negras pela elite europeia. Essa apropriação atua em defesa de uma ideia "brasileira" de autenticidade da mesma elite europeia que exige na sua lógica e prática o desaparecimento físico dos povos nativos originais para que esse novo e especial "Brasil" possa permanecer incontestável e inquestionável. A premissa é que eles estão canibalizando a arte europeia como "nativos" e usando os seus impulsos "brasileiros" para canibalizar e, em seguida, melhorar a arte europeia. Dessa maneira, toda a história da colonização é perdida já que somos, teoricamente, iguais uns aos outros e, assim, póscoloniais.

O Brasil não é especial. Seu início se deu com um bando de criminosos racistas correndo por aí, matando, escravizando e estuprando. Antepassados paternos de Oswald fizeram parte da primeira onda de colonizadores no início do século XVII, na província de Minas Gerais. Esses criminosos estavam à procura de ouro. O eufemismo preferido é "pioneiros de mineração" e, ao longo do caminho, mataram ou escravizaram os nativos locais Puri. Como os Puri se mostraram difíceis de exterminar, foram infectados com varíola. Presume-se que, em 1864, seu extermínio completo foi alcançado com êxito.

Continuando a história de canibalismo no Brasil: no Brasil real (que consiste de povos indígenas, negros e colonizadores), aos que negam o uso contemporâneo do termo colonização, sugiro que atentem para o sentido da existência de um órgão do governo federal brasileiro com o nome de Instituto Nacional de Colonização e Reforma Agrária (INCRA) e, para aqueles que alegam sua não participação na brutalidade colonial, por favor, notem que vocês estão ocupando terras indígenas).

Shirley Krenak explicou: 


\section{ENSAIO}

Durante o massacre (contra nós), lendas de antropofagia e inúmeras outras histórias similares acerca do nosso povo começaram a circular. Um rei que chegou às nossas terras, chamado Dom João VI, em 1808, decidiu declarar guerra ao meu povo, uma guerra chamada "Guerra Justa aos Botocudos". Colonos começaram a receber benefícios fiscais em troca das cabeças dos Krenak. A justificativa para esse nome, "Guerra Justa", era porque o nosso povo estava a "obstruir" o desenvolvimento da região. Para ser honesta, o que o meu povo estava a impedir eram sim os incêndios florestais, a poluição dos rios, a extração da nossa riqueza natural e a nossa dignidade manchada com sangue inocente. E porque eles pensavam que essa terra não tinha dono, decidiram nos exterminar completamente.

Agora, de volta ao tema elites e canibalismo, a fascinação contínua dos euro-brasileiros com o canibalismo pode, talvez, ser um reconhecimento subconsciente do genocídio cometido no Brasil contra a população nativa. Se você considera quem está comendo quem, o nível de canibalização foi surpreendente. Pensa-se que houve cerca vinte a trinta milhões de indígenas no Brasil no começo da colonização portuguesa, em 1500. Em meados do século XX, devido ao genocídio, escravidão e guerras bacteriológicas, a população foi reduzida a cento e oitenta mil pessoas. Nesse mesmo período, em decorrência da colinização, 540 línguas (não dialetos) indígenas foram extintas no Brasil.

Creio que a conversa com Tamar deveria ser re-intitulada: "Mais uma vez uma conversa que falhou na América Colonial".

Em uma conferência sobre "Identidade Cultural e Artística nas Américas”, organizada por Ivo Mesquita, de eminente família eurobrasileira, realizada em São Paulo, em 1991, nenhum povo indígena ou afrobrasileiro foi convidado como representantes de sua cultura. A delegação brasileira, com cerca de uma dúzia de pessoas, todas euro-brasileirss, incluiu Heloisa Buarque de Hollanda, da eminente família Hollanda e também uma feminista com sua publicação no livro da conferência, intitulada "Feminismo: construção de identidade e a condição cultural" (Feminism: constructing identity and the cultural condition).

Perguntei aos delegados brasileiros de um painel: "Por que aqui não há povos indígenas ou afro-brasileiros na condição de delegados?” Uma mulher da delegação respondeu (eu não sei se foi ou Heloisa ou Aracy Amaral, Ana Maria Belluzzo ou Stella Teixeira de Barros) que os 
brasileiros não são racistas e não consideram convidar delegados por "raça" e que eles (os delegados), portanto, representam todos. Nenhum desses palestrantes, altamente qualificados e privilegiados, questionaram sua participação exclusiva como euro-brasileiros no processo de definição do Brasil, que tem a segunda maior população negra do mundo.

Não teria sido um gesto surpreendente de empoderamento se Heloisa Buarque tivesse, ao invés de aceitar o convite de participação, insistido que uma mulher indígena tomasse seu lugar? Ou se, ao perceber que não haveria participação indígena brasileira ou de afro-brasileiros, imediatamente e publicamente renunciasse sua posição como delegada e abandonasse a conferência? Heloisa escreve eloquentemente que a "experiência de mulheres e negros brasileiros continua sendo essencialmente marcada pela intolerância e pelo preconceito sexual ou racial". Por essa razão, mais uma vez, considero interessante notar sua omissão quanto a não presença dos indígenas na referida conferência.

A elite não desiste de seu poder. Não importa quão feminista é.

A conferência Eco-Sindical (Ecologia e Sindicatos) da Força Sindical, em São Sebastião, São Paulo, em 1991, foi a primeira vez que os trabalhadores se reuniram no Brasil para discutir questões ambientais. A Força Sindical é uma organização sindical e como é de costume a maioria dos delegados eram homens. Eu iria falar no primeiro dia, logo após a sessão preliminar. Após o almoço, me perguntaram se eu concordaria em falar no final do dia, porque estávamos atrasados. Eu concordei. No final do dia, perguntaram-me se eu poderia ceder o meu direito de falar. Respondi que não tinha nenhum problema em não falar: sou uma palestrante relutante e estava muito feliz de não estar no olho público. Mas como eu não estava representando a mim mesma, esclareci que era a única palestrante para falar das questões indígenas e insisti que não poderia haver uma conferência em São Sebastião, um dos primeiros enclaves brutais da colonização e da escravidão dos povos indígenas, e não ter palestrante sobre o tema. Acho que, talvez, tenham me pedido para não falar não por eu ser uma mulher, mas, em vez disso, porque os povos indígenas não são vistos como importantes para participar de discussões mais “sérias". Devo 
acrescentar que, embora fosse uma organização da classe trabalhadora, os líderes dessa união eram descendentes de europeus.

Em 1980, no Rio de Janeiro, um programa de liberalização foi iniciado pela ditadura militar (forçado pela revolta popular) e pela Sociedade Brasileira para o Progresso da Ciência (SBPC): foi a celebração de algumas liberdades possíveis. Eu vim para ouvir as discussões feministas. Um par de anos atrás, eu estava em São Paulo e tinha tido uma experiência decepcionante com feministas de lá e esperava que esta vez fosse melhor. Nessa cidade, entrevistei uma romancista e eminente feminista em sua casa. Ao chegar, a escritora abriu a porta e me levou para a sala de estar. No caminho passamos pela cozinha, onde sua empregada estava escutando transmissões num pequeno rádio, após terminar de lavar os pratos de almoço. A escritora exigiu que ela desligasse o rádio e voltasse ao trabalho. Enquanto discutíamos o desenvolvimento do feminismo em São Paulo, a empregada interrompeu para perguntar se o chá era para ser servido na louça do dia-a-dia ou na louça de prata. A escritora, em um tom agudo e indignado, disse-lhe para usar a cabeça.

Em seguida, passei a encontrar um pequeno grupo feminista - devo acrescentar aqui que minha enunciação do Português (ensinada a mim por meus pais que receberam pouca educação formal), muito rapidamente, revela minhas origens de classe -, que tentou me oferecer seus conselhos de especialistas e, como insisti em um discurso mútuo, fui rudemente esnobada.

No simpósio da SBPC, uma das palestrantes feministas foi Pia Matarazzo. $\mathrm{Na}$ época, lembro de feministas brasileiras brancas (não havia nenhum outro tipo visível) me avisando que eu tinha que apoiar Pia Matarazzo, uma mulher de negócios e altamente competente. Ela herdou o império de negócios de seu pai sobre as expectativas de seus irmãos. Meu pai era o motorista de seu pai. Durante o tempo em que meu pai trabalhava para ele, lembro-me que ele e minha mãe comiam um pouco de feijão, bastante arroz, alguns vegetais e nenhuma proteína. Minha irmã e eu dividíamos um iogurte para o jantar. Houve problemas contínuos sobre como obter o suficiente para comer durante a nossa infância. Eu não entendia por que deveria apoiar Pia, que era ligada a esses problemas. 
Nesse simpósio não havia delegados indígenas ou negros. Uma jovem afrobrasileira da plateia, estudante na universidade onde o evento da SPBC foi realizado, falou com uma voz suave e nervosa para as mulheres de classe média euro-brasileiras, que eram as únicas representantes de mulheres do Brasil nesse simpósio. A jovem afro-brasileira perguntou quantas delas tinham sido capazes de vir à reunião porque suas empregadas estavam cuidando de seus maridos e filhos, cozinhando os seus jantares e pegando seus filhos na escola? Ela perguntou por que essas mulheres não tinham sido convidadas. Essas feministas nem sequer se incomodaram em responder. Nenhuma delas. A jovem afro-brasileira foi deixada lá ignorada naquele espaço público de fúria silenciosa e de impotência. Se alguém tiver algum tempo e tiver acesso aos arquivos da SBPC no Rio de Janeiro e puder encontrar os nomes das mulheres que participaram desse simpósio, eu agradeceria.

A elite não desiste do seu poder. A "confusão" que surge no Brasil é que o discurso feminista europeu é a base para o desenvolvimento do feminismo e as mulheres que têm acesso a esse discurso são mulheres altamente educadas de origens privilegiadas. Até as coisas mudarem, muito recentemente, devido à cota racial do governo nas universidades, as mulheres afro-brasileiras e especialmente as mulheres indígenas não tinham acesso às universidades. Nada disso é novo. Mas nos esquecemos de que as Américas são de colonização européia e isso muda a forma como devemos olhar para as discussões que podemos ter. Por causa da colonização, em primeiro lugar, devemos apoiar as lutas indígenas nas Américas e, porque somos feministas, devemos apoiar em primeiro lugar as mulheres indígenas nas Américas. Durante a 29a Bienal de São Paulo (2010), apresentei meu filme, Iracema (de Questembert). O trabalho apresenta uma personagem principal interpretada por Shirley Krenak, a jovem guerreira e líder de sua comunidade na Reserva Krenak em Resplendor, Minas Gerais. Eu perguntei se a Shirley poderia ser convidada para falar sobre a história do seu povo e suas lutas atuais durante os muitos painéis sobre diferentes questões realizadas na Bienal. Perguntei a uma jovem que era uma oficial da Bienal, mas ela não estava interessada e a Shirley não foi convidada e nunca foi convidada para uma conferência organizada 
pelos brasileiros não-indígenas, embora ela seja líder de seu povo e uma palestrante eloquente.

Devemos nos perguntar por que não há mulheres indígenas nas artes, ciências, negócios, etc. (eu tinha pensado em escrever "mulheres indígenas em posições de poder", mas o modelo extremamente tortuoso do racismo não reconhecido assegurou o fato de que, até recentemente, os povos indígenas não tinham acesso à educação. Então, nós não estamos no nível de conversa para falar de posições de poder). Cada vez que vamos a um museu, a uma conferência, a uma exposição em uma galeria, ao consultório médico, a uma aula universitária, é importante nos perguntarmos se há mulheres indígenas. Sabemos que as elites feministas euro-brasileiras não irão se perguntar isso, e pior, elas têm conspirado com o discurso do estado de exclusão que garante sua exclusividade de representação para fazer com que não questionemos essas coisas. São elas que têm o "olho refrescado" e que podem olhar para a cultura "objetivamente". São elas que não são "racistas" e não veem quaisquer raças no Brasil.

São elas que estão continuamente canibalizando os indígenas e os afro-brasileiros enquanto apresentam-se aos brasileiros e ao mundo como brasileiros autênticos. Nesse tipo de narrativa os povos indígenas do Brasil são vistos mais como objetos do que como sujeitos. Como uma mulher euro-brasileira que trabalha com os Ianomâmi disse uma vez: "Nossos índios não são como os da América do Norte", implicando suposta falta de capacidade intelectual (como aos povos indígenas brasileiros, até pouco tempo atrás, era deliberadamente negado o acesso ao ensino superior, os euro-brasileiros, agora os comparam de forma desfavorável a seus primos norte-americanos, que tiveram algumas oportunidades para ir à universidade. Também é preciso ressalvar que os povos indígenas da América do Norte, nacional e internacionalmente, estão organizados desde o início do século XX e essa possibilidade, até recentemente, havia sido negada aos povos indígenas brasileiros pelos próprios brasileiros). Esta euro-brasileira que trabalha com os Ianomâmi também é considerada uma feminista respeitada. As implacáveis negações das elites, seu discurso sobre complexidade e nuances são os jogos que lhes foram ensinados a jogar em uma sociedade paternalista e racista que as feministas brancas 
aceitam voluntariamente porque é aí que continua sua possibilidade de poder.

Na década de 1920, as possibilidades de perspectivas especificamente nativas ou negras foram subordinadas pela elitizada implantação do conceito de canibalismo, para que, setenta anos mais tarde, uma intelectual pudesse descaradamente dizer que "Nós" representamos todos. O real desse "Nós" é um "NÓS" financeiramente privilegiado pelos eurobrasileiros e a política oficial de inclusão, recentemente implantada pelo governo do Partido dos Trabalhadores, tem resultado em uma mudança no discurso de alguns membros da elite que já pensaram ser oportuno renunciar à sua "whitetude" ou "branquetude", o que não significa abrir mão de nenhum dos privilégios que a acompanham.

Repentinamente, algumas pessoas têm se tornado orgulhosamente mestiças, embora seus cabelos loiros e a pele clara não as impeça de entrar em imponentes galerias com seguranças afro-brasileiros na porta de entrada. Uma artista euro-brasileira com um cargo de professora universitária de artes (nem preciso dizer que não existem pessoas indígenas que ocupem esse cargo e duvido que exista um intelectual negro que o faça), recentemente, me disse que não sabe qual é sua “cor". É muito fácil. Eu gostaria de ter a graça de uma resposta rápida do tipo "entre em uma boutique em seu bairro chique, entre em uma galeria no seu bairro e veja quantos afro-brasileiros você acha que estão fazendo a limpeza ou manutenção do local? A sua cor de pele não se reflete nos seus colegas da sua escola de arte? Quando entra em um museu você sente medo que um guarda te chame em voz alta e diga que você não é permitida, porque você não pertence a esse lugar?" É assim que você sabe de que "cor" você é.

No Brasil, raça não pode ocupar uma posição secundária no feminismo, mas deve ser simultânea. Caso contrário, estaremos apoiando os canibais, os descendentes de europeus que, social e economicamente, continuam no poder e continuam a comandar o discurso enquanto negam aos povos indígenas e afro-brasileiros qualquer possibilidade de inclusão nesse mesmo discurso.

Data de recebimento: 05/04/2018

Data de aceite: 30/05/2018 